\title{
Desafios e conquistas da educação do campo na legislação brasileira: Um olhar para o sudoeste do Paraná
}

\author{
Challenges and Achievements of Rural Education in Brazilian Legislation: \\ A Look to the South-West of Paraná
}

\author{
Mariéli Maria Pauli ${ }^{1}$ e Bruno dos Santos Simões ${ }^{2}$ \\ ${ }^{1}$ Universidade Estadual do Oeste do Paraná, Campus de Francisco Beltrão, PR, Brasil \\ mariellypauly@hotmail.com \\ ${ }^{2}$ Universidade Federal de Santa Catarina, Bolsista do CNPq, SC, Brasil \\ profsimoesfisica@gmail.com
}

\begin{abstract}
Resumo
Educação do campo é direito dos povos do campo ou pessoas que se identificam com o mesmo e tem seu sustento proveniente de atividades lá desenvolvidas, ao acesso à educação, que lhes permita inserir-se num processo de construção de conhecimento, mas que também sejam respeitados conforme os conhecimentos que já possuem acerca do local em que vivem. Deste modo, esta pesquisa tem por objetivo verificar como a Educação do Campo se apresenta na legislação brasileira, além de evidenciar o cumprimento ou não de leis que guiam a área. Para tal, fizemos um levantamento de escolas do campo no sudoeste do Paraná, a fim de averiguar o cumprimento de leis no que se refere ao estabelecimento da Educação Básica para sujeitos do campo. Assim, observamos que apesar da oferta do Ensino Fundamental nessa modalidade, o Ensino Médio, em geral, ainda precisa ser cursado em escolas urbanas, o que não compatibiliza com diversos documentos oficiais.
\end{abstract}

Palavras-chave: Educação do Campo; Legislação para escolas do campo; Escolas do campo no sudoeste do Paraná, Políticas públicas para a Educação do Campo.

\begin{abstract}
Rural Education is a right of rural communities, of people that identify themselves with it or of groups that make their living from rural activities. Access to education is guaranteed for them in a way to allow their insertion in a process of knowledge construction, but also to value their own knowledge related to the place where they live. Thus, this research has as goal to verify how Rural Education is presented in legislation, besides to highlight the accomplishment, or not, of laws that guide the field. Thereunto, we made an search in rural schools from south-west of Paraná, in order to verify the implementation of the legislation related to the establishment of Basic Education focused on rural subjects. Therefore, we note that despite the offer of Elementary School in that genre, High School, in general, still needs to be fulfilled in urban schools, what is not compatible with many oficial documents.
\end{abstract}

Keywords: Rural Education, Legislation for rural schools; Rural schools from south-west of Paraná; Public policy. 


\section{Introdução}

Ter acesso à educação é um direito de todos, e é assegurado pela Constituição Federal de 1988. A Educação do Campo, especificamente na formação dos sujeitos do campo, é o direito desses povos em ter acesso a uma educação pensada para eles, levando em consideração o local em que vivem, a realidade à qual estão inseridos e a história que carregam, visando valorizar o seu espaço (o campo), sua cultura, seus saberes e experiências.

Desta forma, ao longo dos anos, estes sujeitos tiveram muitas conquistas. Conquistas estas efetivadas principalmente com: a Resolução CNE/CEB 1, de 3 de abril de 2002, que institui as Diretrizes Operacionais para a Educação Básica nas Escolas do Campo. Este documento visa a adaptação das escolas do campo às Diretrizes Curriculares Nacionais da Educação; e o Decreto no 7.352, de 4 de novembro de 2010, que dispõe sobre a política de educação do campo e o Programa Nacional de Educação na Reforma Agrária - PRONERA, que tem por objetivo ampliar e qualificar a oferta de educação básica e superior para as populações do campo.

Contudo, Lima (2014) tece críticas ao modelo de políticas públicas para a educação do campo. Para esta autora, estas medidas beneficiam de maneira muito tímida as pessoas que realmente deveriam ser assistidas por tais documentos. Além disso, Lima questiona a relevância das políticas de educação do campo para o Estado (alinhavado à aspectos pedagógicos, muitas vezes desconexos do aspecto político; busca pela manutenção do sistema de grupos sociais), e para os movimentos sociais (uma forma de resistência ao capitalismo; busca pela autonomia do campo; e pela igualdade dos grupos sociais).

De modo semelhante, Hage (2014) aponta para uma precarização da educação do campo evidenciando que, pouco menos de $7 \%$ das crianças acessam a educação infantil na creche, e cerca de $66,8 \%$ a pré-escola. Contudo, sua principal crítica fica em relação aos cerca de 90\% que atingem o Ensino Fundamental, pois ainda hoje vemos um contingente significativo de estudantes que são impostos à um ensino multisseriado e unidocente.

Segundo dados da Coordenação de Educação do Campo do Ministério da Educação (MEC), existem atualmente 48.875 escolas multisseriadas no Brasil, as quais representam $56,45 \%$ das Escolas do Campo. Nelas atuam 70 mil docentes e estudam 1,3 milhão de estudantes nos anos iniciais do Ensino Fundamental. Em grande medida, essas escolas se constituem na única alternativa para esses sujeitos estudarem nas próprias comunidades em que vivem, ficando expostos a um conjunto de situações que não favorecem o sucesso e a continuidade dos estudos e muito menos a permanência desses sujeitos no campo, evidenciando, inclusive, o descumprimento da legislação vigente que já aponta marcos operacionais da qualidade que deveriam ser alcançados na educação básica nas escolas do campo (HAGE, 2014, p. 142).
Hage (2014, p. 143) alerta também à formação dos 342.845 professores que atuam no campo no Brasil. Em consulta a dados do INEP, o autor afirma que quase a metade destes docentes não possui educação superior, cerca de 46,7\%. Destes, 97,4\% possuem apenas o Ensino Médio e 2,6\% possuem apenas o Ensino Fundamental.

Tais aspectos são apenas alguns dos desafios enfrentados na Educação do Campo. Assim, o objetivo deste artigo é argumentar sobre cumprimento da legislação referente à Educação do Campo na região sudoeste do Paraná.

\section{Educação do Campo: uma história de conquistas}

Ainda hoje podemos observar uma contínua insistência na ideia de que existe um conhecimento pronto e unificado, oriundo de uma parcela da população dos centros urbanos considerados civilizados. E que este deveria ser imposto às outras pessoas que apresentassem competência para assimila-lo, inclusive aos habitantes do campo. Com isso, ao mesmo tempo em que ocorre uma desvalorização dos saberes do campo, percebemos que "[...] se ofereceu, a uma pequena parcela da população rural, uma educação instrumental, reduzida ao atendimento de necessidades educacionais elementares e ao treinamento de mão-de-obra" (BRASIL, 2007, p. 10).

A Educação do Campo tem um significado de grande valor, principalmente para os sujeitos do campo: homens, mulheres, trabalhadores de todas as idades, gêneros, de diferentes origens e culturas, que carregam consigo um sentimento de pertencimento ao campo e de afeto pelo seu espaço de trabalho, a terra. Um povo que tem uma história marcada por rejeição, desigualdades e injustiças. Mas que apresenta, sobretudo, uma história de luta por seus direitos, resistência diante dos obstáculos impostos pelo diversos grupos e entidades ligadas por objetivo unilateral, a capitalização dos recursos agrários, e aos poucos a conquista de seus direitos (CALDART, 2011).

A Educação do Campo consiste no direito das pessoas do campo à educação, pensada conforme o contexto em que estão inseridos, valorizando sua história de luta e seus saberes. São considerados sujeitos do campo: os agricultores familiares, os extrativistas, os pescadores artesanais, os ribeirinhos, os assentados e acampados da reforma agrária, os trabalhadores assalariados rurais, os quilombolas, os caiçaras, os povos da floresta, os caboclos e outros que produzam suas condições de existência a partir do trabalho no meio rural (CALDART, 2011). Neste mesmo sentido, a autora complementa que a Educação do Campo tem por objetivo educar o povo que está inserido e que trabalha no campo, para que estes se tornem capazes de direcionar seu próprio destino.

Segundo Caldart, Cerioli e Fernandes (2011) existe a necessidade de realizar uma Educação do Campo que identifique e valorize o campo como um lugar de trabalho, e que auxilie na criação de projetos de desenvolvimento 
do campo. O desenvolvimento do campo com base na agricultura familiar, mostrando que ao contrário do que muitos discursos impõem, não é um lugar de atraso e regresso e sendo essa uma forma de inserir-se na sociedade, visando apresentar a sua importância e da relação dos moradores com ele.

Até o ano de 1930, não havia uma preocupação especial com os sujeitos do campo, uma vez que estes, não eram vistos e nem valorizados como cidadãos. Além disso, o campo era visto como um local de atraso. A partir da década de 1960, temendo as consequências do intenso fluxo migratório das pessoas do campo para as cidades, que vinha ocorrendo, o governo inicia um plano de oferta de uma educação rural que prepare o homem do campo adaptando-o ao meio em que está (BRASIL, 2007).

Na década de 1960, iniciou-se um movimento de educação popular, onde professores, movimentos religiosos e partidos políticos de orientação de esquerda lutavam dentre outras coisas por democracia, que permitisse a participação popular nas decisões políticas. Nesse processo de resistência contra o governo, em meados de 1980 passaram a incluir em seu "pacote de exigências" a educação do campo (BRASIL, 2007).

Conforme a Lei de Diretrizes e Bases da Educação Nacional (LDB) de 1961, a partir deste momento, os governos precisavam atender as necessidades das pessoas que viviam na área rural, para tanto, deveriam manter escolas rurais para atendimento dos mesmos (BRASIL, 2007)

Um importante fator para o desenvolvimento da Educação do Campo foi a luta dos Trabalhadores Rurais Sem-Terra pela reforma agrária ainda no início da década de 80.

A Educação do Campo [...] nasceu da combinação das lutas dos sem-terra pela implantação de escolas públicas nas áreas de reforma agrária com as lutas de resistência de inúmeras organizações e comunidades camponesas para não perder suas escolas, suas experiências de educação, suas comunidades, seu território, sua identidade (CALDART, 2008, p. 67).

À medida que as famílias, passaram a se organizar para a luta por terras, preocuparam-se com uma educação digna para os filhos. Assim, nesse mesmo contexto de lutas, algumas mães e professores começaram a organizar uma luta também pelo acesso dos filhos à educação. Mais tarde, ganham apoio dos pais e de líderes do MST que juntos lutam também pela criação de escolas nos espaços de lutas, nos assentamentos e acampamentos do MST. Assim, a necessidade por escolas que visam ensinar os trabalhadores semterra e seus filhos, passa a ser uma exigência do MST (SOUZA, 2008).

Em julho de 1997, ocorre em Brasília o primeiro ENERA (Encontro Nacional de Educadoras e Educadores da Reforma Agrária), uma ação conjunta do MST, CNBB,
UnB, UNESCO e UNICEF ${ }^{1}$. O objetivo desse encontro era discutir ideias e preocupações referentes à Educação do Campo. Neste encontro, surge a ideia de promover um Congresso, desta forma, em julho de 1988, ocorreu a I Conferência Nacional Por uma Educação do Campo, em Luziânia, no estado de Goiás, em que foi enfatizado a luta por políticas públicas em favor do campo e de todos os trabalhadores e trabalhadoras desse espaço pensada para eles, como um direito que é concedido para qualquer outra pessoa (PARANÁ, 2006, p. 19).

A Articulação Nacional por uma Educação do Campo, criada também em 1988, culminou em 2002, com a participação do Conselho Nacional de Educação (CNE), na instituição das Diretrizes Operacionais para a Educação Básica nas Escolas do Campo, e em 2003, na criação do Grupo Permanente de Trabalho de Educação do Campo (GPT). Esse grupo, instituído pelo MEC, tinha como função, reunir as entidades e movimentos sociais ligados à educação do campo e juntos cuidar de questões como as políticas públicas que promovem o desenvolvimento de projetos de desenvolvimento do campo na educação do campo (ARROYO; FERNANDES, 1999).

A criação das Diretrizes Operacionais para a Educação Básica nas Escolas do Campo em 2002, foi um acontecimento muito importante, pois com esse documento a educação passa a ter mais oportunidades de se concretizar, como um projeto que defende a valorização dos sujeitos do campo, seus saberes e o direito de acesso à uma educação planejada de acordo com a realidade local onde estão inseridos.

[...] o reconhecimento e valorização da diversidade dos povos do campo, a formação diferenciada de professores, a possibilidade de diferentes formas de organização da escola, a adequação dos conteúdos às peculiaridades locais, o uso de práticas pedagógicas contextualizadas, a gestão democrática, a consideração dos tempos pedagógicos diferenciados, a promoção, através da escola, do desenvolvimento sustentável e do acesso aos bens econômicos, sociais e culturais (BRASIL, 2007, p. 17).

O processo de luta pela educação no campo, é uma prática marcada pela injustiça, indiferença e desigualdades. Mas apesar desses sujeitos serem oprimidos nesse processo e terem muitas vezes seus direitos negados, são também sujeitos de luta e resistência. Ao longo da história da Educação do Campo, ocorreram muitas lutas envolvendo diversos movimentos sociais e sindicais, por uma política pública que garantisse acesso à educação do campo como um direito dos sujeitos do campo, visto como uma forma de manter seus territórios, suas identidades, sua cultura (CALDART, 2011).

Por fim, em novembro de 2010, mais um importante

1 Movimento dos Trabalhadores Rurais Sem Terra, Conferência Nacional dos Bispos do Brasil, Universidade de Brasília, Organização das Nações Unidas para Educação, Ciência e Cultura e o Fundo das Nações Unidas para as Crianças e Jovens. 
direito foi conquistado. Nesta data foi publicada, por meio do Decreto nำ 7.352, a política de Educação do Campo, um decreto que traz para a população do campo a garantia do direito de acesso à educação completa. Conforme este decreto, as escolas do campo teriam um sistema educacional completo, ofertando educação infantil, ensino fundamental, ensino médio, técnico e superior.

\section{A Educação do Campo amparada pela legislação: até que ponto?}

Ao longo deste trabalho sinalizamos algumas conquistas da Educação do Campo materializadas na forma da Lei. Porém, ao investigarmos a efetividade destas, podemos observar que nem todos os direitos conquistados são devidamente cumpridos. Para tanto, analisaremos algumas Leis e documentos que envolvem a temática, em seguida, discutiremos tal aspecto abordando a realidade vivida na região sudoeste do Paraná.

Vamos trazer como ponto de partida, a Constituição Federal de 1988, com a publicação deste documento, a educação progride de modo positivo. É possível verificar isso nos artigos 205, 206 e 208. No artigo 205, fica estabelecido que "[...] a educação, direito de todos e dever do Estado e da família, será promovida e incentivada com a colaboração da sociedade [...]" (BRASIL, 1988, p. 177). No artigo 206 "[...] o ensino será ministrado com [...] igualdade de condições para o acesso e permanência na escola (BRASIL, 1988, p. 177) e no artigo 208 “[...] o acesso ao ensino obrigatório e gratuito é direito público subjetivo" (BRASIL, 1988, p. 178)".

A educação gratuita é um direito de todos os cidadãos, sendo que ela deve ser obrigatoriamente ofertada pelo Estado, e não poderia deixar de contemplar também os povos que vivem no campo.

Na sequência, trazemos a Lei de Diretrizes e Bases de 20 de dezembro de 1996 (LDB/96), em que a educação do campo é abordada com maior atenção. Em seu artigo 21, a LDB trata sobre a formação dos níveis de educação que "compõe-se de: I - educação básica, formada pela educação infantil, ensino fundamental e ensino médio; II - educação superior" (BRASIL, 1996, p. 11). Assim, tem direito à educação os sujeitos do campo, principalmente as crianças, os adolescentes e os jovens que no mínimo deverão receber uma formação educacional básica, da educação infantil ao ensino médio. Já o artigo 28 , argumenta em prol dos sujeitos do campo, pois este estabelece que:

Na oferta de educação básica para a população rural, os sistemas de ensino promoverão as adaptações necessárias à sua adequação às peculiaridades da vida rural e de cada região, especialmente: I- conteúdos curriculares e metodologias apropriadas às reais necessidades e interesses dos alunos da zona rural; II- organização escolar própria, incluindo adequação do calendário escolar às fases do ciclo agrícola e às condições climáticas; III- adequação à natureza do trabalho na zona rural (BRASIL, 1996, p.13).

Conforme artigo 5ํㅜ das Diretrizes Operacionais para a Educação Básica nas Escolas do Campo, as propostas para a educação nas escolas do campo além de cumprir com o estabelecido na LDB, devem ser elaboradas respeitando os alunos, seus saberes, sua realidade e a diversidade do local em que estão inseridos:

As propostas pedagógicas das escolas do campo, respeitadas as diferenças e o direito à igualdade e cumprindo imediata e plenamente o estabelecido nos artigos 23, 26 e 28 da Lei 9.394, de 1996, contemplarão a diversidade do campo em todos os seus aspectos: sociais, culturais, políticos, econômicos, de gênero, geração e etnia (BRASIL, 2002, p. 1).

Nesse sentido, as Diretrizes Curriculares da Educação do Campo também nos mostram que no processo de ensino na Educação do Campo é importante o respeito da cultura e saberes do aluno e que os conhecimentos dos mesmos devem se fazer presente nas propostas pedagógicas (PARANÁ, 2006). Apesar disso, o mesmo documento nos afirma que isso não ocorre de fato, pois o currículo usado para trabalhar é urbano, é definido conforme as características desse meio, além disso,

a cultura, os saberes da experiência, a dinâmica do cotidiano dos povos do campo, raramente são tomados como referência para o trabalho pedagógico, bem como para organizar o sistema de ensino, a formação de professores e a produção de materiais didáticos" (PARANÁ, 2006, p. 28).

Longe de permitir qualquer forma de exclusão, é garantido aos povos do meio rural, uma educação pensada conforme o espaço em que estão inseridos e respeitando os conhecimentos e a cultura que carregam consigo, visando valorizar a formação como cidadãos capazes de intervir positivamente na sociedade trazendo benefícios a todos, porém não se verifica seu cumprimento.

Para finalizar, apresentamos o Decreto no 7.352 de 4 de novembro de 2010, que nos informa que haverá a oferta de formação completa na Educação Básica para as pessoas do campo, nos locais em que vivem. Neste ponto, trazemos uma contradição: conforme dados de um levantamento que realizamos no site da Secretaria de Educação do Estado do Paraná (SEED)², verificamos que a maioria das escolas do campo da região Sudoeste do Paraná, por exemplo, ofertam somente Ensino Fundamental, exigindo em alguns casos, que estudantes do Ensino Médio, precisem se deslocar do local em que vivem para a área urbana para estudar.

Percebe-se que o que ocorre ainda é apenas um cumprimento parcial da legislação. Principalmente em relação ao Decreto no 7. 352/2010 e dos artigos da LDB/1996 no

2 Informações disponíveis no endereço eletrônico: www.diadia. pr.gov.br. 
que se refere a não oferta de formação básica completa nas escolas do campo.

Essa situação culmina em problemas para a educação e os sujeitos do campo, desde o próprio deslocamento em si, à uma certa descaracterização da identidade e origem desses jovens. Levando-os, por vezes, a desvalorizar o campo e tentar inserir-se no meio urbano, adaptando-se às características desse novo ambiente, que na escola, geralmente, lhes é apresentado como superior ao meio rural.

E então, aqui nos questionamos, até que ponto a educação do campo pode sentir-se amparada pela legislação?

\section{A Educação do Camponosudoeste do Paraná}

A região sudoeste do Paraná está dividida em quatro microrregiões, a considerar: Capanema, Francisco Beltrão, Palmas e Pato Branco, pelas quais, estão distribuídos 42 municípios. A mesorregião abrange uma área de 11.651,90 Km² e sobre ela está distribuída uma população residente em 2010 de 497.127 pessoas, sendo 30,42\% rural (SALDANHA, 2014).

Desde o início da colonização e ocupação do Sudoeste do Paraná, a produção alimentar, tornou-se uma atividade muito desenvolvida. A princípio, os indígenas com caça e pesca, e posteriormente a agricultura rudimentar com os caboclos que aqui chegaram. Aos poucos, a agricultura familiar foi se constituindo também neste espaço. Para Corona, 2003,

o aumento da demanda por alimentos baratos e acessíveis à classe trabalhadora da cidade motivou a ocupação das novas fronteiras do país, e o desenvolvimento da agricultura familiar [...]. O Sudoeste do Paraná foi sendo ocupado até 1940 pela população indígena e cabocla [...]. As práticas agrícolas dos caboclos desenvolviam-se a partir de dois recursos técnicos fundamentais (CORONA, 2003, p 5).

A agricultura é um componente muito importante na economia do Paraná, e não é diferente na mesorregião Sudoeste, onde a atividade também representa uma fatia importante da balança comercial da região. Saldanha (2014), com base em dados do censo agropecuário de $2006^{3}$, argumenta que em 2006, a produção dos estabelecimentos agropecuários do Sudoeste representa 9,23\% da produção total do estado. Destes, 14,91\% é oriundo da agricultura familiar (SALDANHA, 2014).

A partir disso, verifica-se a importância da agricultura familiar no Sudoeste do Paraná, tanto para a economia do estado, e posteriormente do país, quanto para todos que se beneficiam com a produção alimentar com vistas à preservação ambiental, mas principalmente para os agricultores familiares, sujeitos do campo e para o desenvolvimento territorial. Para Santos (2009),

3 Disponível em: http://www.sidra.ibge.gov.br/bda/pesquisas/ca/ defaultFAO.asp? $\mathrm{z}=\mathrm{p} \& \mathrm{O}=2 \& \mathrm{i}=\mathrm{P}$ poderíamos inferir que a agricultura familiar se constitui num dos elementos de unicidade e favorável ao desenvolvimento territorial (SANTOS, 2009, p. 5).

Deste modo, percebe-se a necessidade de manter os jovens no campo, para que estes possam contribuir com a manutenção da prática da agricultura familiar, e deste modo, valorizem o trabalho, a cultura e os saberes gerados neste espaço, levando para as próximas gerações os verdadeiros valores de suas identidades e origens.

Pensar as escolas do campo requer levar em consideração a constituição da localidade e conhecer as pessoas que ocupam este espaço. Em nosso país há uma grande diversidade de pessoas e atividades ligadas ao campo. E no Paraná não é diferente. Neste estado é possível encontrar nas escolas do campo filhos de pequenos produtores, alguns deles oriundos de assentamentos do MST, empregados de latifúndios, indígenas, entre outros.

Desta forma, os princípios da Educação do Campo que devem orientar a elaboração e a concretização das propostas de educação às populações do campo (Decreto no 7.352), apontam no sentido de se considerar as especificidades do campo na concepção de uma educação que surge pela luta social, da prática coletiva e para a geração de conhecimento para transformação da própria realidade (SOUZA, 2011). Concepção essa, influenciada por trabalhos de Paulo Freire $(2006 ; 2011)$ sobre as contraditórias situações de opressão vivenciadas pelos sujeitos do campo, a partir da qual mostra possibilidades de se repensar o processo educacional, valorizando criticamente a cultura dos sujeitos por meio do diálogo e problematização das situações contraditórias.

Nessas condições, conforme o Decreto no 7.352/2010, as escolas do campo devem oferecer educação básica completa, porém, em uma consulta à Secretaria de Educação do Estado do Paraná (SEED), sobre as escolas do campo do Sudoeste estado do Paraná, pertencentes aos núcleos de: Dois Vizinhos, Francisco Beltrão e Pato Branco, verificaram que as maiorias destas não oferecem Ensino Médio, apenas o Ensino Fundamental II, de $6^{0}$ ao $9^{\circ}$ ano.

Segundo informações obtidas na página oficial da Associação dos Municípios do Sudoeste do Paraná (AMSOP), a região sudoeste do Paraná é composta por 42 municípios, que de acordo com a Secretaria de Estado de Educação do Paraná, estão distribuídos nos três Núcleos Regionais de Educação supraditos, totalizando 277 instituições de ensino. Destas, 88 são escolas do campo, incluindo as escolas indígenas, mas somente 22 oferecem Ensino Fundamental e Médio. Nesta pesquisa, a atenção volta-se para o fato de ser baixo o número de escolas do campo que oferecem Ensino Médio. A tabela a seguir sintetiza estes dados.

Em relação à Tabela 1, cabe ressaltar que a Secretaria de Educação utiliza dois tipos de classificação para referir-se as escolas do campo: escolas indígenas do campo e, simplesmente, escolas do campo. Além disso, das escolas 
Tabela 1 - Relação de escolas por Núcleo Regional de Educação

\begin{tabular}{ccccc}
\hline Núcleo & $\begin{array}{c}\text { Número de } \\
\text { escolas }\end{array}$ & $\begin{array}{c}\text { Número de } \\
\text { escolas do campo }\end{array}$ & $\begin{array}{c}\text { Número de } \\
\text { escolas indígena } \\
\text { do campo }\end{array}$ & $\begin{array}{c}\text { Número de } \\
\text { escolas do campo } \\
\text { com ensino médio }\end{array}$ \\
\hline $\begin{array}{c}\text { Dois vizinhos } \\
\text { Francisco Beltrão }\end{array}$ & 42 & 12 & 0 & 1 \\
Pato Branco & 110 & 44 & 0 & 3 \\
Total & 75 & 29 & 3 & 18 \\
\hline
\end{tabular}

Fonte: os autores

mencionadas na tabela, 3 das escolas do Núcleo de Pato Branco são classificadas apenas como escolas indígenas.

Com isso, nossos apontamentos estão em consonância com os trabalhos de Munarim (2011), Hage (2014), Locks e Munarim (2012), Fischer, Fogaça e Roesler (2008) e Paraná (2008) no que tange o não cumprimento da legislação em relação às escolas do campo.

Hage (2014), ao indicar que, no estado do Pará, o acesso ao Ensino Médio em escolas do campo, quando existe, é deficitário em diversos aspectos. E alguns casos, quando se é ofertado esta etapa de ensino, ela ocorre em regime modular, em que o docente se desloca até as escolas e ministram as aulas durante determinado período concentrado.

Locks e Munarim (2012) nos trazem a realidade dos jovens do campo no estado de Santa Catarina. Por não terem acesso ao ensino médio e técnico no local em que vivem, ou seja, no próprio campo, esses jovens acabam migrando para a cidade, deixando o campo e a família, pois é a única opção que lhes é oferecida.

Fischer, Fogaça e Roesler (2008), apontam que, no Brasil, o acesso à educação para o nível médio ainda é precário, e que muitos jovens não cursam o Ensino Médio no período oportuno. Essa situação faz com que muitos destes jovens que vivem no campo precisem deixar este espaço para estudar no perímetro urbano, levando-os a encontrar na cidade melhores condições de trabalho e de sobrevivência, se comprado ao campo.

Por fim, Paraná (2008), expõe certa preocupação com os jovens do campo que enfrentam uma série de obstáculos que dificultam a permanência dos mesmos neste local, é baixo o número de jovens que tem acesso ao Ensino Médio e profissional no campo, ensino este que dificilmente atende a realidade deles visando a sua permanência no campo.

\section{Considerações finais}

Ter acesso à educação, à escola e/ou ao ensino, é um direito de todos. Assim, a Educação do Campo ocorre em escolas inseridas em área rural ou urbana, mas que tenham uma educação caracteristicamente pensada sobre e para o campo. Que atenda os sujeitos que se identificam com o campo, que tenham sua economia oriunda de atividades realizadas no meio rural. Nesse contexto, muitos foram os desafios encontrados pelos sujeitos envolvidos na luta por uma Educação do Campo. Mas também podemos destacar as diversas conquistas registradas na forma da Lei.

A Constituição Federal de 1988 estabelece que o Estado deve promover uma educação gratuita para todos. A LDB/1996 esclarece que a Educação Básica é composta por: Educação Infantil, Ensino Fundamental e Ensino Médio. Nesse sentido, o Decreto n⿳ำ 7.352/2010 ressalta que as escolas do campo devem oferecer educação básica completa.

Entretanto, verificamos que apesar das muitas conquistas ocorridas que estão atualmente estabelecidas na legislação, existem falhas no cumprimento adequado destas. O que prejudica, principalmente, os sujeitos que dependem das políticas públicas que lhes garantam o cumprimento dos seus direitos.

Desta forma, sinalizamos a necessidade de se manter a vigilância em relação à efetivação da legislação vigente para a Educação do Campo no sudoeste do Paraná. Visto que, além de ser um elemento de direito destes sujeitos, o deslocamento até os centros urbanos para o estudo pode se tornar um complicador para muitos dos estudantes atendidos por estas escolas. Pois estes, geralmente, necessitam de transporte, o que nem sempre é acessível.

Neste ponto, cabe a reflexão de Munarim (2011):

Ademais, a importância dessa luta setorial por Educação do Campo, da parte desses sujeitos protagonistas, está justamente no fato de que eles extrapolam a setorialização ou compartimentação das políticas. Exigem que as políticas para essa educação se façam inerentes a um projeto de campo e de País conforme almejam. Embora não tenham força para impor a efetivação desse projeto - nem de País e nem sequer de campo - de toda forma, demonstram firmemente que eles existem como sujeitos propositores e ativos no cenário nacional. Isso é muito importante no processo de construção democrática de uma nação como o Brasil, em que muita gente vive no campo e do campo (MUNARIM, 2011, p. 62).

Por fim, alertamos à importância de investigações que busquem verificar e qualificar a efetivação de políticas públicas, especialmente àquelas voltadas ao campo, pois este é um espaço rico de pessoas, de história e 
ainda representa uma parcela importante da balança comercial de nosso país.

\section{Referências}

ARROYO, M. G.; CALDART, R. S.; MOLINA, M. C. (Orgs.). Por uma educação do campo. $5^{\mathrm{o}}$ ed. Petrópolis: Vozes, 2011.

ARROYO, M. G.; FERNANDES, B. M. A educação básica e o movimento social no campo. Brasília, DF: Articulação Nacional Por Uma Educação Básica do Campo, 1999. Disponível em: <http://portal.mec.gov.br/secad/arquivos/ pdf/educacaodocampo/edbasicapopular.pdf $>$ Acesso em 10 jan. 2016.

BRASIL. Conselho Nacional De Educação: Diretrizes Operacionais para a Educação Básica nas Escolas do Campo. Brasília-DF, 2002. Disponível em: <http://www. gepec.ufscar.br/textos-1/textos-educacao-do-campo/ diretrizes-operacionais-para-a-educacao-basica-nasescolas-do-campo/view> Acesso em: 11 dez. 2015;

Constituição da República Federativa do Brasil de 1988. Disponível em: <http://www.planalto.gov.br/> Acesso em 10 dez. 2015.

. Decreto-Lei no 7.352, de 4 de novembro de 2010. Dispõe sobre a política de educação do campo e o Programa Nacional de Educação na Reforma Agrária PRONERA. Disponível em: <http://www.planalto.gov. br/ccivil_03/_ato2007-2010/2010/decreto/d7352.htm> Acesso em: 10 dez. 2015.

. Lei no 9. 394, de 20 de dezembro de 1996. Estabelece as diretrizes e bases da educação nacional. Disponível em: <http://www.planalto.gov.br/ccivil_03/ Leis/L9394.htm> Acesso em 07 dez. 2015.

Ministério da Educação: Caderno de Educação do Campo. Brasília-DF, 2007. Disponível em: <http:// portal.mec.gov.br/secad/arquivos/pdf/educacaocampo. pdf $>$ Acesso em 10 jan. 2016.

FISCHER, C. W.; FOGAÇA, J.; ROESLER, V. L. Práticas educativas no ensino médio. In: CAMPOS, C. S. S; MACHADO, C. L. B; PALUDO, C (Organizadores) Teoria e Prática da educação do campo: análises de experiências. Brasília: MDA, 2008.
FREIRE, P. Extensão ou comunicação? Rio de Janeiro: Paz e Terra, 2011.

FREIRE, Paulo. Educação como prática da liberdade. Rio de Janeiro: Paz e Terra, 2006.

HAGE, S. M. Movimentos sociais do campo e educação: referências para análise de políticas públicas de educação superior. Revista Eletrônica de Educação, v. 8, n. 1, p.133-150, 2014.

LIMA, R. R. F. A política pública da educação do campo em feira de Santana: entre o dizer e o fazer. 2014, 174p. Dissertação (Mestrado em Educação) - Universidade Estadual de Feira de Santana, Programa de Pós-Graduação em Educação, Feira de Santana, 2014.

LOCKS, G. A.; MUNARIM, A. Educação do campo: contexto e desafios desta política pública. Olhar de professor, v. 15, n. 1, p. 87-90, 2012.

MUNARIM, A. Educação do Campo no cenário das políticas públicas na primeira década do século 21. Em Aberto, v. 24, n. 85, p. 51-63, 2011.

PARANÁ. Secretaria de Estado da Educação: Cadernos Temáticos da Educação do Campo. Curitiba, 2008. Disponível em: < http://www.educadores.diaadia.pr.gov. br/arquivos/File/cadernos_tematicos/caderno_tematico_ campo01.pdf> Acesso em: 10/05/2016.

. Secretaria de Estado da Educação: Diretrizes Curriculares da Educação do Campo. Curitiba, 2006. Disponível em: $<$ http://www.educadores.diaadia.pr.gov. br/arquivos/File/diretrizes/diretriz_edcampo.pdf $>$ Acesso em 10 jan. 2016.

SALDANHA, R. K. O perfil da agricultura familiar do sudoeste paranaense segundo o histórico da economia agrícola da região e as estatísticas mais recentes. Monografia (Especialização em Ciências Econômicas)Universidade Federal do Paraná, Curitiba, 2014. Disponível em: <http://dspace.c3sl.ufpr.br/dspace/ handle/1884/38270> Acesso em jan. 2016.

SOUZA, M. A. de. Educação do Campo: Políticas, práticas pedagógicas e produção científica. 